\title{
Effects of electrical stimulation and stretching on the adaptation of denervated skeletal muscle - implications for physical therapy
}

\section{Efeitos da eletroestimulação e do alongamento muscular sobre a adaptação do músculo desnervado - implicações para a fisioterapia}

Tania F. Salvini, João L. Q. Durigan, Sabrina M. Peviani, Thiago L. Russo

\begin{abstract}
Background: This review will describe the main cellular mechanisms involved in the reduction and increase of myoproteins synthesis commonly associated with muscle atrophy and hypertrophy, respectively. Objective: We analyzed the effects of electrical stimulation (ES) and stretching exercise on the molecular pathways involved in muscle atrophy and hypertrophy. We also described the main effects and limits of these resources in the skeletal muscle, particularly on the denervated muscle. Discussion: Recently, our studies showed that the ES applied in a similar manner as performed in clinical practice is able to attenuate the increase of genes expression involved in muscle atrophy. However, ES was not effective to prevent the loss of muscle mass caused by denervation. Regarding to stretching exercises, their mechanisms of action on the denervated muscle are not fully understood and studies on this area are scarce. Studies from our laboratory have found that stretching exercise increased the extracellular matrix remodeling and decreased genes expression related to atrophy in denervated muscle. Nevertheless, it was not enough to prevent muscle atrophy after denervation. Conclusions: In spite of the use of stretching exercise and ES in clinical practice in order to minimize the atrophy of denervated muscle, there is still lack of scientific evidence to justify the effectiveness of these resources to prevent muscle atrophy in denervated muscle.
\end{abstract}

Keywords: rehabilitation; electric stimulation; peripheral nerve injury; muscle atrophy; stretching.

\section{Resumo}

Contextualização: Esta revisão abordará os principais mecanismos celulares envolvidos na redução e aumento da síntese de mioproteínas comumente associadas às situações de atrofia e hipertrofia muscular, respectivamente. Objetivo: Analisaremos os efeitos da estimulação elétrica (EE) e do exercício de alongamento sobre as vias moleculares envolvidas na atrofia e hipertrofia muscular. Serão descritos os principais efeitos e os limites desses recursos no músculo esquelético, particularmente sobre o músculo desnervado. Discussão: Recentemente, nossos estudos mostraram que a EE, aplicada de modo semelhante ao realizado na prática clínica, é capaz de amenizar o aumento da expressão de genes envolvidos na atrofia muscular. Entretanto, a EE não foi efetiva para deter a perda de massa muscular decorrente da desnervação. Em relação ao alongamento, seus mecanismos de ação sobre o músculo desnervado não são totalmente conhecidos, e os trabalhos nessa área são escassos. Estudos do nosso laboratório identificaram que o alongamento aumentou o remodelamento da matriz extracelular e diminuiu a expressão de genes relacionados à atrofia no músculo desnervado. Porém, também não foi suficiente para impedir a atrofia muscular após a desnervação. Conclusões: Apesar do uso da EE e do alongamento muscular na prática clínica, com objetivo de minimizar a atrofia do músculo desnervado, ainda há carência de informações científicas que justifiquem a eficácia desses recursos para prevenir a atrofia no músculo desnervado.

Palavras-chave: reabilitação; estimulação elétrica; lesão nervosa periférica; atrofia muscular; alongamento.

Received: 10/17/2011 - Revised: 12/12/2011 - Accepted: 01/15/2012 


\section{Skeletal muscle atrophy and hypertrophy pathways $: \because \therefore$.}

The adaptability of the muscle tissue is also called muscle plasticity. These adaptations may occur in various situations such as physical activity and muscle disuse, stretching, injury and regeneration, neuromuscular diseases, among others. The mechanisms involved in this adaptation should be known by physical therapists as it contributes to scientifically support their clinical practice.

\section{Muscle atrophy}

Muscle atrophy is characterized by a reduction in the protein content, organelles, cytoplasm, in the fiber diameter, in the production of muscle strength and in the resistance to fatigue ${ }^{1-3}$. The main factors that cause muscle atrophy are: denervation, musculoskeletal injury, joint immobilization, ligament and joint injuries, joint inflammation, prolonged bed rest, glucocorticoid treatment, sepsis, cancer and aging ${ }^{1,4,5}$.

Atrophy begins with the reduction in muscle tension, which will reflect in both the reduction of the synthesis and in the increase of protein degradation ${ }^{6}$. There are four systems of proteolytic degradation involved in muscle atrophy: lysosomal proteases system (cathepsin), calpain calciumdependent signaling, caspases signaling and the ubiquitinproteasome system ${ }^{1,3,6,7}$. The lysosomal proteases system plays a key role in the degradation of membrane proteins, including receptors, ligands, channels and transporters (for review, see Mayer ${ }^{8}$ ). The calpain system (cysteine protease $\mathrm{Ca}^{2+}$ - dependent) acts together with the ubiquitin-proteasome for the degradation of intact myofibrils ${ }^{9,10}$. This system operates in the cleavage of sarcomeric proteins (such as titin, protein that maintains the alignment of the sarcomere), which allows the release of myofibrils to be ubiquitinated and, hence degraded in the proteasome $e^{6}$. The caspases have also a role in the degradation of the actin-myosin complex suggesting a similar role of calpains making the myoproteins available to the degradation by the ubiquitin-proteasome system $^{6}$. In addition, caspases are also involved in apoptosis of myonuclei, which can be induced by changes in the dynamics of the sarcoplasmic reticulum, by specific apoptosis receptors and by changes in mitochondrial function ${ }^{11}$.

The ubiquitin-proteasome system is the main protein degradation pathway in eukaryotic cells and is also the most important in muscle proteolysis ${ }^{1,7,12,13}$. The ubiquitination (i.e. the conjugation process of the protein to be degraded) is a reversible post-translational modification that forms one isopeptide linkage between the ubiquitin and the substrate-protein and involves at least the action of three classes of enzymes. In this process the E3 class is responsible for the specificity of protein ubiquitination being able to recognize and select a set of substrates for degradation ${ }^{13}$.

The main E3 described are atrogin-1, also known as MAFbx, and family members of MuRF1 (Muscle RING Finger 1). The atrogin-1 is involved in processes such as sepsis, cachexia, diabetes mellitus, uremia, starvation, immobilization and denervation ${ }^{1,3,7}$. The MuRF1 is associated with ubiquitination of the myofibrillar components, such as titin, heavy and light chain of myosin and myosin-binding protein $\mathrm{C}^{4,10}$, and also the misalignment and degradation of myofibrin proteins ${ }^{10}$. The atrogin- 1 and the MuRF1 are selectively expressed in muscle tissue (cardiac and skeletal) of humans and other animals in situations that involves muscle atrophy ${ }^{3,4}$.

There is a common genetic program involved in muscle proteolysis regardless of its etiology, however the signaling pathways that modulate this system are distinct ${ }^{1,3,14}$. It is well established that the serum levels of proinflammatory cytokines, particularly the IL- 1 and the TNF- $\alpha$, are elevated in cachectic patients contributing to muscle atrophy ${ }^{1-3}$, whereas the oxidative stress is also an important inducer of muscle atrophy in both disuse as well as in the muscle cachexia ${ }^{14}$.

\section{Muscle hypertrophy}

Muscle hypertrophy is defined by an increase in protein content, organelles, cytoplasm and in the muscle fiber diameter $^{15}$, resulting in functional changes such as increased muscle strength. Satellite cells or myogenic progenitor cells play an extremely important role in this process and several factors may modulate its activation/differentiation ${ }^{16}$. It should be highlighted the role of myogenic regulatory factors (MRFs), which can promote the proliferation and differentiation of skeletal muscle during myogenesis as well as their adaptive processes in the adult muscle ${ }^{17}$, and thus modulate the division of satellite cells and incorporation of these cells to pre-existing fibers or to the formation of new fibers in the muscle hypertrophy $^{18}$. The myogenic regulatory factors (MRFs) are composed of MyoD (or Myf-3), Myf-5, myogenin (or Myf-1) and MRF-4 or Myf-6/herculin ${ }^{17}$.

The IGF-I (type I insulin-like growth factor) is described as a major molecular factor involved in skeletal muscle hypertrophy (Figure 1). Its interaction with the muscle membrane receptor (IGF-1R) activates the IGF/PI3K/Akt pathway, which promotes increased protein synthesis with direct action in the myonuclei, as well as through the activation, proliferation and fusion of the satellite cell ${ }^{19-21}$. A recent review of Scicchitano, Rizzuto and Musarò ${ }^{22}$ showed the complex of transcription 

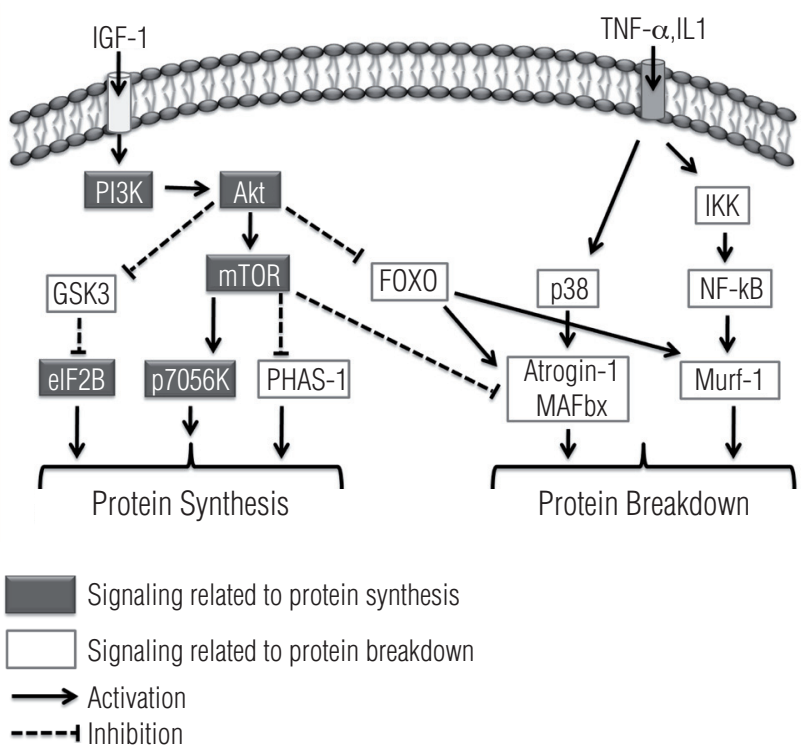

PI3K=fosfaditil inositol 3-kinase; Akt=serine-threonine kinase; GSK3=glycogen synthase kinase 3; mTOR=protein target of rapamycin; FOXO=Transcription Factors Fork; elF2B=eukaryotic initiation factor $2 \mathrm{~B}$. Figure adapted from Glass ${ }^{1}$.

Figure 1. It can be seen to the left signaling triggered by IGF-1 that results in muscle hypertrophy by activation of PI3K that starts a chain sequence of activation (Akt, mTOR, and p7056K elF2B). Moreover, the signaling pathways triggered by TNF- $\alpha$ and IL-1 that leads to muscle atrophy are identified. The increase in MuRF1 gene expression occurs through signaling mediated by NF-kB, while the expression of atrogin-1 is increased by p38. Interestingly, activation of Akt signaling inhibits transcription of genes atrogin-1/MAFbx and MuRF1 (associated with atrophy) through inactivation of FOXO.

and RNA processing of IGF-1 and the difficulties in identifying factors involved in muscle hypertrophy.

In this context, six sequences responsible for coding different types of IGF-1 have been identified in rodents. These coding sequences are called exons and they are separated by non-coding sequences called introns. According to the transcription of IGF-1 gene various isoforms can be produced. For example, the IGF-1 transcripts initiating at exon 2 predominate in the liver, are highly growth hormone-responsive (GH), being the largest endocrine effector. On the other hand, those who are initiated at exon 1 are widely expressed in all tissues of the body and are less affected by circulating GH levels, possibly performing autocrine or paracrine functions ${ }^{22}$.

Furthermore, another confounding factor in the understanding of the types and functions of IGF-1 produced is related to the RNA processing (splicing), i.e to the joining of different segments of the coding sequences (exons) and to the removal of non-coding (introns) of RNA. Accordingly, two variations have been well-documented in rodents, the Eb, which is more abundant in the liver and the Ea present in all tissues ${ }^{22}$. This Eb isoform (IGF-1Eb) is also present in skeletal muscle and can be regulated by stretching exercise, being called mechano-growth factor or $\mathrm{MGF}^{23}$. However, technical advances are still needed for a detailed description of the MGF.

Based on this information, it is understood that IGF-1 can act as a circulating hormone or as a local growth factor. Essentially, its function will be dependent on the tissue where it is expressed and the type of IGF-1 produced. For example, the increase of expression of cardiac IGF-1 isoform prevents the activation of cell death in the viable myocardium after infarction. However, the increased expression of other isoforms, other than the cardiac, induces a progressive maladaptive hypertrophy. Such findings demonstrate the need to understand the autocrine and paracrine action of these local IGF-1 isoforms ${ }^{24,25}$.

An important study showed that the increase in the muscle expression of a local IGF-1 isoform (mIGF-1) is able to induce muscle hypertrophy with an increase in strength in transgenic mice and to minimize sarcopenia in animals by maintaining the regenerative capacity of these muscles by stimulation of satellite cells and current embryonic stem cell recruitment ${ }^{19}$. Such evidence indicates that mIGF-1 is able to promote the quality of the cellular environment, ensuring the highest efficiency of muscle regeneration process, being a powerful strategy to minimize the sarcopenia.

Interestingly, when the muscle atrophy pathways are activated, the IGF-1-mediated signaling will be reduced, which reduces the Akt signaling and allows FOXO to transcribe the genes of muscle atrophy (Figure 1). Thus, there is an interrelationship between the muscle hypertrophy and atrophy pathways, which modulates the gene transcription involved in muscle adaptation in response to the increased demand of work or due to the disuse in the muscle skeletal system ${ }^{1,3,7}$.

Another factor identified as a negative regulator of skeletal muscle growth is the myostatin, a transforming growth factor beta (TGF- $\beta$ ) superfamily member ${ }^{26}$. Myostatin inhibits the expression of myogenic regulatory factors and is related to activation of the satellite cells. Animals that do not express the myostatin showed an increase in the number and proliferation of satellite cells in the muscle fibers, resulting in a higher muscle mass ${ }^{27}$. It is noteworthy that an animal that express a mutated form of myostatin (which did not express this protein) present muscle hypertrophy and hyperplasia, as in the case of the Belgian Blue cattle ${ }^{26}$.

It is important to highlight that with the advance of molecular biology several mechanisms related to muscle atrophy and hypertrophy were elucidated and pharmacologic/genetic intervention has been proposed to minimize the adverse effects of muscle disuse and in situations of neuromuscular diseases. In an experimental model of amyotrophic lateral sclerosis has been shown that the muscle expression of IGF-1 is crucial, 
since it promotes a protective effect both for the muscles and for motor neurons, being a strong candidate for the treatment of this condition ${ }^{28}$. In mice with Duchenne muscular dystrophy, myostatin inhibition shows therapeutic potential for increasing the skeletal muscle mass, increase muscle regeneration and reduced fibrosis, however this strategy must be associated with gene therapy in order to add the improvement of the muscle fibers regeneration with the muscle function ${ }^{29}$.

Interestingly, the physical resources used routinely in clinical practice of physical therapy are also able to act directly on the muscle atrophy and hypertrophy molecular pathways. Following, the effects of two widely used resources in physical therapy, the electrical stimulation (ES) and muscle stretching exercise will be discussed in the treatment of denervated muscle.

\section{The use of electrical stimulation (ES) in physical therapy $: \because$.}

The ES is widely used and disseminated by physical therapists and it has numerous indications such as the induction of tissue repair ${ }^{30}$, analgesia ${ }^{31}$, electrical diagnosis ${ }^{32}$, function training in hemiparetic pacients ${ }^{33}$ and muscle strength in healthy and hemiparetic subjects ${ }^{34,35}$. There is controversy over the use of ES in the treatment of several conditions and more controlled trials are needed to characterize the effects of this resource, as well as the identification of more efficient and safe parameters of stimulation.

\section{Electrical stimulation and muscle adaptation}

The ES has been recommended as an important tool in the rehabilitation of subjects in post-neurological injuries, such as stroke $^{34}$. Among them, the Functional Electrical Stimulation (FES) has been widely investigated with good results (for review, see Sheffler and $\left.\mathrm{Chae}^{34}\right)$. Lindquist et al..$^{33}$ observed that FES facilitated the ankle dorsiflexion during gait training on a treadmill with partial body weight support in subjects with chronic hemiparesis. Another study have investigated the effect of FES in the function and in the range of motion of the upper limb of hemiparetic subjects and reported a significant improvement in function and prevention of subluxation of the shoulder related to the use of FES only when the FES was initiated within the first month post-stroke. Chronic patients (longer than one year of stroke) did not benefit from the treatment ${ }^{36}$.

In addition to the relevant findings related to the use of FES in neurological rehabilitation, the ES has been also used in healthy subjects in order to maximize strength gains during resistance training. However, the this topic remains controversial. A study of Avila, Brasileiro and Salvini ${ }^{35}$, which have investigated the effect of an ES program (Russian current, frequency of $2500 \mathrm{~Hz}, 50$ bursts/s, pulse duration of $200 \mu \mathrm{s}$ ) associated with isokinetic training for the knee extensors (three series of ten repetition at $30^{\circ} / \mathrm{s}$, twice a week, for four weeks) in healthy young subjects, showed that the ES did not potentiate the training results in these individuals.

Moreover, a recent systematic review (see Filipovic et al. ${ }^{37}$ ) showed that the choice of electrical parameters and the regime of stimulation are essential to obtain satisfactory results in strength gain. The authors showed that significant gains are related to stimulation with intensities equal or greater than $50 \%$ of maximum voluntary contraction of the individual. Furthermore, frequency values higher than $60 \mathrm{~Hz}$, pulse duration from 200 to $400 \mu \mathrm{s}$ and duty cycle between 20 and 25\% are important for optimal results. Finally, the stimulation regimes should consider, on average, four weeks of training with three sessions a week of 17 minutes each and 6 seconds of contraction. Nevertheless, the authors also report that the motivation and pain perception of the individual are factors that must be considered because they affect the ability to tolerate higher stimulation intensities, interfering therefore the training results.

The ES seems to have positive effects on muscle strength in situations where there is a change of motor response, such as after the reconstructions of the anterior cruciate ligament (ACL) of the knee (for review, see Kim et al. ${ }^{38}$ ). In this injury, the quadriceps muscle suffers an arthrogenic muscle inhibition, and abnormal afferents arising from the knee joint may alter the excitability of the spinal reflex pathways, reducing the activation of the quadriceps muscle by inhibiting the alpha motoneurons. Accordingly, the ES has been indicated to help restore the strength of the quadriceps muscle by facilitation and increased recruitment of its motor units. Despite the wide variation in electrical parameters used in the literature, it is suggested that the use of ES associated with physical exercise leads to gains in the strength of the quadriceps muscle and has been recommended in rehabilitation after reconstruction of $\mathrm{ACL}^{38}$.

\section{Electrical stimulation and treatment of denervated muscle}

The use of ES on denervated muscle has been a topic of controversy for decades. In general, a series of studies state that ES would be able to maintain muscle mass and strength until the reinnervation occurs, while other studies show that the ES may delay neuromuscular recovery, inhibiting 
reinnervation and, therefore, should not be used in the treatment of denervated muscles.

A series of studies from our laboratory and from collaborators have investigated the effects of ES on the adaptation of denervated muscle in animal models ${ }^{32,39-43}$. The use of animal models allows a greater control over the variables and avoids important ethical issues involved in this type of study in humans. We observed that ES applied similarly to that performed in clinical practice, that is, considering the changes in muscle excitability due to denervation, using surface electrodes and performing the stimulation in treatment sessions, is able to minimize the expression of atrophy genes, such as the atrogin- $1^{39}$ and the MuRF- ${ }^{41}$; to minimize the expression of negative mass control, such as myostatin ${ }^{41}$; and to minimize the expression of transcription and hypertrophy, such as MyoD ${ }^{39,41}$. However, the reduction of expression of these genes was not sufficient to protect the muscle mass, that is, the ES was not able to stop the loss of muscle mass due to denervation ${ }^{39,41}$. These experiments used a exponential monopolar electric current with pulse duration equal to twice the chronaxie value, being the stimulation performed on alternated days $s^{39,40}$ or daily ${ }^{41,42}$.

An important aspect to be observed by researchers and therapists while assessing the effects of ES on the denervated muscle is to consider, besides the effectiveness of treatment on muscle atrophy, the safety of electrical stimulation on the reinnervation process. To investigate whether ES affects factors involved in the reinnervation of denervated muscle fibers is essential for safe indication of this therapeutic resource. Recently, it was demonstrated that the use of ES in the initial phase after nerve crush injury in rats was harmful, leading to a delay of functional recovery, muscle hipoexcitability and severe muscle atrophy ${ }^{43}$. Another study that applied ES directly on the crushed nerve of mice also showed signs of delay in the nerve regeneration process, such as edema, reduced organization of axonal cytoarchitecture and fewer number of myelin fibers ${ }^{44}$. Finally, studies in humans that have used ES on muscle with chronic denervation also showed no protective effect on muscle mass and no functional recovery ${ }^{45}$.

Although controversy remains about the use of ES in the treatment of denervated muscles, some studies using animal models have shown that the electrical parameters and the form of stimulation are crucial. It seems that there are some key factors in preserving muscle mass and strength, such as the number of daily contractions and the distribution of these contractions throughout the day. A very interesting study from Dow et al. ${ }^{46}$ showed that 200 daily contractions are effective to prevent mass and strength loss in denervated muscles. However, this effect occurs only if the interval between the muscle contractions induced by electrical stimulation does not exceed eight hours ${ }^{47}$. It should be noted that in this study, such effects were obtained in muscles of rats using implanted electrodes and also in fast-twitch muscles, such as the extensor digitorum longus. Similar studies in humans are needed to evaluate whether this ES program would also have effectiveness to maintain muscle mass. Furthermore, in this ES program the implantation of electrodes was obtained by invasive method, which also is unusual in humans.

Future studies should consider the following assumptions: check the effectiveness of ES on muscle mass and strength; ascertain its safety while studying factors of muscle reinnervation, excitability and especially muscle function; consider the stimulation parameters that have shown some protective effect on denervated muscles; assess its effects on different types of muscles (slow and fast) and, mainly using stimulation techniques similar to those used in clinical practice. The findings presented here reinforces the fact that the ES, as used by physical therapists for the treatment of denervated muscles, remains controversial and it has not been shown effective to prevent muscular atrophy after denervation.

\section{Stretching exercise as a therapeutic resource : $:$.}

Muscle stretching is a technique widely used to increase range of motion (ROM) in both healthy subjects and during rehabilitation. In animal models, it has been observed that the stretching exercise can prevent the proliferation of connective tissue, the loss of sarcomeres in series and muscle atrophy ${ }^{48,49}$. In humans, it has been observed that stretching exercises increase the ROM, decrease the passive stiffness of the muscletendon unit and the tonic reflex activity suggesting an increase in muscle length and extensibility ${ }^{50-52}$. The musculoskeletal adjustments related to stretching exercise depend on the intensity, duration and frequency of the stretching exercise is performed, generating elastic and plastic responses of these structures, influencing therefore the flexibility and the generation of total muscle strength ${ }^{50-52}$.

In the 70's, important studies were developed using animal models to investigate the effect of stretching in the plasticity of the skeletal muscle, which showed that the muscle fibers adapt to the stretching by the addition of new sarcomeres in series at their ends, without changing the amount of connective tissue $^{53,54}$. Although these studies contribute to the understanding of muscle adaptation due to stretching, the immobilization in stretching position is not normally used in humans, where the immobilizations are held with the joints in a functional position. On the other hand, short periods of muscular stretching (from 30 seconds to 1 minute) have been recommended for the 
treatment of shortened muscles due to its effectiveness in the gain of ROM and flexibility ${ }^{51,52,55}$.

The scientific findings observed to date indicate that stretching is able to promote the increase of protein synthesis ${ }^{56,57}$. As the mechanism of hypertrophy involves an increase of protein synthesis and accumulation an increase in expression of muscle-specific genes is required. It is interesting to observe how the mechanical stimulus of stretching affects the muscle fiber and this signal is translated into the cell, being this process known as mechanotransduction, as shown in Figure 2. The mechanical stimulus is initially transmitted to the components of the extracellular matrix (ECM), which is mainly composed of collagens and glycoproteins that involving the muscle fibers. These muscle fibers have proteins in their membrane, called integrins, which are able to detect the mechanical stimulus and then transmit the signal to inside the fiber, activating a series of proteins that affect the nucleus and then change the transcription of muscle-specific genes, which subsequently regulates the translation of proteins in the cytoplasm ${ }^{58}$. This is how a mechanical stimulus causes a series of intracellular changes, such as increase in protein synthesis and, consequently, in muscle strength and joint range of motion.

A series of studies from our laboratory has investigated the effect of stretching in the muscle adaptation in animal models, since there is methodological limitation for performing this type of study in humans. It was observed that short periods of passive stretching (ten repetitions of stretching exercises of 1 minute with 30 seconds rest between repetitions), mimicking exercise programs recommended for rehabilitation and sports activities were effective to change the expression of three genes related to hypertrophy (MyoD), atrophy (atrogin-1) and control of muscle mass (myostatin), both after a single session of passive stretch and after seven sessions of stretching ${ }^{59}$. Furthermore, passive stretching maintained for 30 consecutive minutes changed only MyoD and atrogin- ${ }^{48}$. It was interesting to note that stretching programs did not cause injury in the muscle fibers. Our results indicated that muscle remodeling promoted by passive stretching involves the activation of different signaling pathways (hypertrophy and atrophy). Future studies that characterize these pathways, as well as possible changes in the function of these muscles will help to better understand the muscle changes associated with the stretching.

Another relevant aspect in the assessment of the skeletal muscle exposed to stretching should be to check the remodeling of the connective tissue, for example, by the activity of matrix metalloproteases (MMPs), since they are involved in the degradation of ECM components and contribute to its remodeling ( for review, Carmeli et al. ${ }^{60}$ ). However, we observed in animal models that passive stretching sessions (ten repetition of stretching exercise of one minute with 30 seconds rest between repetitions) did not change the activity or the gene expression of MMP-2 and -9, indicating that this type of stretching seems

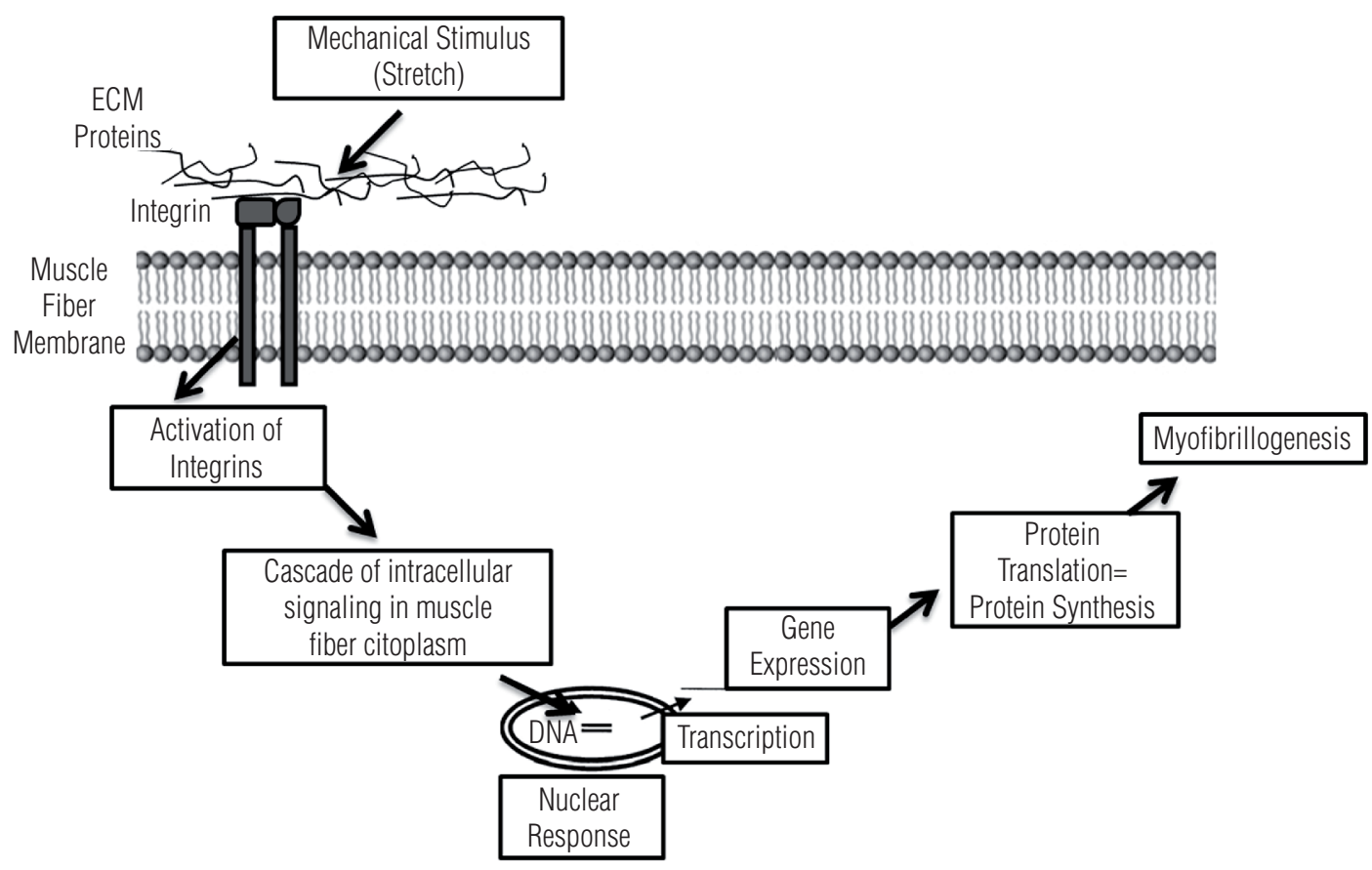

Figure 2. Mechanism of cell mechanotransduction. The mechanical stimulus promoted, for example, by stretching is transmitted to the components of extracellular matrix (ECM) which in turn activate membrane integrins. This activation promotes a cascade of intracellular signaling by altering the transcription of muscle-specific genes that regulate the translation of proteins and myofibrillogenesis (adapted from De Deyne ${ }^{58}$ ). 
not to be effective to remodel the ECM by this pathway ${ }^{61}$. Further studies are needed in order to investigate the effect of a greater number of sessions, as well as the types of stretching on the content and quality of different types of muscle collagen, and the involvement of other pathways besides MMPs involved in ECM remodeling.

On the other hand, this same type of passive stretching, when performed daily in the muscle after joint immobilization for three weeks induced a molecular reorganization of the collagen bands, suggesting the connective tissue remodeling ${ }^{49}$. Despite the methodological differences between studies it appears that the factor immobilization was critical in the ECM disorganization and that stretching had a favorable effect on their remodeling, suggesting an improvement in strength transmission and interaction of the muscle with the connective tissue.

\section{The stretching in the treatment of the denervated muscle}

An important therapeutic question is whether stretching exercises can be beneficial for denervated muscles. Given the adaptation deriving from the muscle denervation, the biggest challenge for the rehabilitation is to prevent or reduce muscle atrophy, until the muscle can be reinervated. Muscle stretching has been used in the denervated muscle in order to induce mechanical muscle stimulus, to maintain the ROM and to prevent deformities.

The mechanisms of action of stretching on the denervated muscle are not yet fully understood and studies in this topic are scarce, particularly because of the difficulty in conducting studies in humans. Accordingly, studies in animal models have allowed a better understand of the role of stretching on denervated muscle. A very interesting study showed that the adaptation of the muscle to the length, which occurs by the addition or removal of sarcomeres in series do not depend of neural activity ${ }^{50}$ and may stimulates protein synthesis and attenuates the atrophy. Therefore, stretching could be a resource in the treatment of denervated muscles.

Few studies have assessed the effects of stretching on denervated muscles. Loughna and Morgan $^{62}$ observed that the stretching by immobilization in dorsiflexion during five days reduced the effects of denervation on the gene expression of myosin heavy chain (MHC) I and II of the soleus and gastrocnemius muscles. This study suggests that stretching can modulate the expression of MHC independent of innervation and also highlights the importance of "tension" generated by stretching in regulating the expression of these contractile proteins. Another study also showed that the stretching of the denervated soleus muscle performed 40 minutes per day (six times/week, four weeks) prevented atrophy of type I fibers and the conversion of type I to type II fibers in the first two weeks after denervation ${ }^{63}$.

In the attempt to investigate the effect of a period of stretching (12 minutes) in the treatment of the denervated muscle during the first week after denervation, recent studies from our laboratory identified an increased in the activity and in the gene expression of MMP-2 in the denervated muscle, suggesting therefore a role in remodeling the $\mathrm{ECM}^{42}$ and a decrease in the accumulation of gene expression related to muscle atrophy, such as atrogin-1, MuRF-1 and miostatin ${ }^{41}$. However, this stimulation was not sufficient to prevent the atrophy of the muscle fiber after denervation. These results indicate that the period of stretching appears to be essential in the treatment of the denervated muscle, since longer periods of stretching, such as 40 minutes a day, as performed by Sakakima and Yoshida ${ }^{63}$ were effective in preventing the atrophy of the first 15 days after denervation.

Another important issue is related to the number of daily sessions of stretching. In ES, the best results in controlling the atrophy of the denervated muscle were obtained when the sessions were distributed throughout the day (four daily sessions, with an interval of 8 hours between them $)^{46}$. Therefore, further studies are needed to assess whether the application of stretching distributed throughout the day could minimize or prevent post-denervation muscle atrophy.

In general, the studies that used the model of stretching in the denervated muscle suggest an effect on the muscle remodeling and on the ECM in the first weeks after denervation. However, there are also few studies that assess the effect of stretching after long periods of denervation when atrophy has already been installed.

\section{Conclusions : :}

Despite the use of ES and muscle stretching in clinical practice in order to minimize the atrophy of denervated muscle, there is still lack of scientific information to justify the effectiveness of these resources to prevent atrophy in the denervated muscle.

\section{Acknowledgements : :}

This study received financial support from the Fundação de Amparo à Pesquisa do Estado de São Paulo (FAPESP), São Paulo, Brazil and postdoctoral fellowships from FAPESP and from Coordenação de Aperfeiçoamento de Pessoa de Nível Superior (CAPES), Brasilia, DF, Brazil 
1. Glass DJ. Skeletal muscle hypertrophy and atrophy signaling pathways. Int J Biochem Cell Biol. 2005;37(10):1974-84.

2. Bassel-Duby R, Olson EN. Signaling pathways in skeletal muscle remodeling. Annu Rev Biochem. 2006;75:19-37.

3. Sandri M. Signaling in muscle atrophy and hypertrophy. Physiology (Bethesda). 2008;23:160-70

4. Bodine SC, Latres E, Baumhueter S, Lai VK, Nunez L, Clarke BA, et al. Identification of ubiquitin ligases required for skeletal muscle atrophy. Science. 2001;294(5547):1704-8.

5. Ramirez C, Russo TL, Sandoval MC, Dentillo AA, Couto MA, Durigan JL, et al. Joint inflammation alters gene and protein expression and leads to atrophy in the tibialis anterior muscle in rats. Am J Phys Med Rehabil. 2011;90:930-9.

6. Jackman RW, Kandarian SC. The molecular basis of skeletal muscle atrophy. Am J Physiol Cell Physiol. 2004;287(4):C834-43.

7. Glass DJ. Signaling pathways perturbing muscle mass. Curr Opin Clin Nutr Metab Care. 2010;13(3):225-9

8. Mayer RJ. The meteoric rise of regulated intracellular proteolysis. Nat Rev Mol Cell Biol. 2000;1(2):145-8.

9. Solomon V, Baracos V, Sarraf P, Goldberg AL. Rates of ubiquitin conjugation increase when muscles atrophy, largely through activation of the N-end rule pathway. Proc Natl Acad Sci USA. 1998:95(21):12602-7.

10. Cohen S, Brault JJ, Gygi SP, Glass DJ, Valenzuela DM, Gartner C, et al. During muscle atrophy, thick, but not thin, filament components are degraded by MuRF1-dependent ubiquitylation. J Cell Biol. 2009;185(6):1083-95.

11. Primeau AJ, Adhihetty PJ, Hood DA. Apoptosis in heart and skeletal muscle. Can J Appl Physiol. 2002;27(4):349-95

12. Hershko A, Ciechanover A. The ubiquitin system. Annu Rev Biochem. 1998:67:425-79.

13. Glickman $\mathrm{MH}$, Ciechanover $\mathrm{A}$. The ubiquitin-proteasome proteolytic pathway: destruction for the sake of construction. Physiol Rev. 2002;82(2):373-428

14. Powers SK, Kavazis AN, McClung JM. Oxidative stress and disuse muscle atrophy. J Appl Physiol. 2007;102(6):2389-97.

15. Russell B, Motlagh D, Ashley WW. Form follows function: how muscle shape is regulated by work. J Appl Physiol. 2000;88(3):1127-32.

16. Adams GR. Satellite cell proliferation and skeletal muscle hypertrophy. Appl Physiol Nutr Metab. 2006:31(6):782-90.

17. Sabourin LA, Rudnicki MA. The molecular regulation of myogenesis. Clin Genet. 2000;57(1):16-25.

18. Hyatt JPK, Roy RR, Baldwin KM, Wernig A, Edgerton VR. Activity-unrelated neural control of myogenic factors in a slow muscle. Muscle Nerve. 2006;33(1):49-60.

19. Musarò A, McCullagh K, Paul A, Houghton L, Dobrowolny G, Molinaro M, et al. Localized Igf-1 transgene expression sustains hypertrophy and regeneration in senescent skeletal muscle. Nat Genet. 2001;27(2):195-200.

20. Goldspink G. Gene expression in muscle in response to exercise. J Muscle Res Cell Motil. 2003;24(2-3):121-6

21. Mattsson A, Svensson D, Schuett B, Osterziel KJ, Ranke MB. Multidimensional reference regions for IGF-I, IGFBP-2 and IGFBP-3 concentrations in serum of healthy adults. Growth Horm IGF Res. 2008;18(6):506-16

22. Scicchitano BM, Rizzuto E, Musarò. Counteracting muscle wasting in aging and neuromuscular diseases: the critical role of IGF-1. Aging (Albany NY). 2009;1(5):451-7.

23. McKoy G, Ashley W, Mander J, Yang SY, Williams N, Russell B, et al. Expression of insulin growth factor-1 splice variants and structural genes in rabbit skeletal muscle induced by stretch and stimulation. J Physiol. 1999;516(Pt 2):583-92.

24. Delaughter MC, Taffet GE, Fiorotto ML, Entman ML, Scwartz RJ. Local insulin-like growth factor I expression induces physiologic, then pathologic, cardiac hypertrophy in transgenic mice. FASEB J. 1999;13(14):1923-9.

25. Leri A, Liu Y, Wang X, Kajstura J, Malhotra A, Meggs LG, et al. Over-expression of insulin-like growth factor-1 attenuates the myocyte renin-angiotensin system in transgenic mice. Circ Res. 1999;84(7):752-62

26. McPherron AC, Lawler AM, Lee SJ. Regulation of skeletal muscle mass in mice by a new TGFbeta superfamily member. Nature. 1997;387(6628):83-90.
27. Thomas M, Langley B, Berry C, Sharma M, Kirk S, Bass J, et al. Myostatin, a negative regulator of muscle growth, functions by inhibiting myoblast proliferation. J Biol Chem. 2000;275(51):40235-43.

28. Dobrowolny G, Giacinti C, Pelosi L, Nicoletti C, Winn N, Barberi L, et al. Muscle expression of a local Igf-1 isoform protects motor neurons in an ALS mouse model. J Cell Biol. 2005;168(2):193-9.

29. Trollet C, Athanasopoulos T, Popplewell L, Malerba A, Dickson G. Gene therapy for muscular dystrophy: current progress and future prospects. Expert Opin Biol Ther. 2009;9(7):849-66

30. Houghton PE, Campbell KE, Frase CH, Harris C, Keast DH, Potter PJ, et al. Woodbury MG Electrical stimulation therapy increases rate of healing of pressure ulcers in community-dwelling people with spinal cord injury. Arch Phys Med Rehabil. 2010;91(5):669-78.

31. Sluka KA, Bailey K, Bogush J, Olson R, Ricketts A. Treatment with either high or low frequency TENS reduces the secondary hyperalgesia observed after injection of kaolin and carrageenan into the knee joint. Pain. 1998;77(1):97-102

32. Russo TL, França CN, Castro CES, Salvini TF. Alterations of the chronaxie, reobase and accomodation in denervated skeletal muscle submitted to electrical stimulation. Rev Bras Fisioter. 2004;8(2):169-75

33. Lindquist ARR, Prado CL, Barros RML, Mattioli R, Lobo da Costa PH, Salvini TF. Gait training combining partial body-weight support, a treadmill, and functional electrical stimulation: effects on poststroke gait. Phys Ther. 2007;87(9):1144-54.

34. Sheffler LR, Chae J. Neuromuscular electrical stimulation in neurorehabilitation. Muscle Nerve 2007;35(5):562-90.

35. Avila MA, Brasileiro JS, Salvini TF. Electrical stimulation and isokinetic training: effects on strength and neuromuscular properties of healthy young adults. Rev Bras Fisioter. 2008;12(6):435-40.

36. Wang RY, Yang YR, Tsai MW, Wang WT, Chan RC. Effects of functional electric stimulation on upper limb motor function and shoulder range of motion in hemiplegic patients. Am J Phys Med Rehabil. 2002;81(4):283-90.

37. Filipovic A, Kleinöder $H$, Dörmann U, Mester J. Electromyostimulation - a systematic review of the influence of training regimens and stimulation parameters on effectiveness in electromyostimulation training of selected strength parameters. J Strength Cond Res 2011:25(11):3218-38

38. Kim KM, Croy T, Hertel J, Saliba S. Effects of neuromuscular electrical stimulation after anterior cruciate ligament reconstruction on quadriceps strength, function, and patient-oriented outcomes: a systematic review. J Orthop Sports Phys Ther. 2010;40(7):383-91.

39. Russo TL, Peviani SM, Freria CM, Gigo-Benato D, Geuna S, Salvini TF. Electrical stimulation based on chronaxie reduces atrogin-1 and MyoD gene expressions in denervated rat muscle. Muscle Nerve. 2007;35(1):87-97.

40. Russo TL, Peviani SM, Durigan JLQ, Salvini TF. Electrical stimulation increases matrix metalloproteinase-2 gene expression but does not change its activity in denervated rat muscle. Muscle Nerve. 2008;37(5):593-600.

41. Russo TL, Peviani SM, Durigan JL, Gigo-Benato D, Delfino GB, Salvini TF. Stretching and electrical stimulation reduce the accumulation of MyoD, myostatin and atrogin-1 in denervated rat skeletal muscle. J Muscle Res Cell Motil. 2010:31(1):45-57.

42. Peviani SM, Russo TL, Durigan JL, Vieira BS, Pinheiro CM, Galassi MS, et al. Stretching and electrical stimulation regulate the metalloproteinase-2 in rat denervated skeletal muscle. Neurol Res. 2010;32:891-6.

43. Gigo-Benato D, Russo TL, Geuna S, Domingues NR, Salvini TF, Parizotto NA. Electrica stimulation impairs early functional recovery and accentuates skeletal muscle atrophy after sciatic nerve crush injury in rats. Muscle Nerve. 2010;41(5):685-93.

44. Baptista AE, Gomes JR, Oliveira JT, Santos SM, Vannier-Santos MA, Martinez AM. High- and low-frequency transcrutaneous electrical nerve stimulation delay sciatic nerve regeneration after crush lesion in the mouse. J Peripher Nerv Syst. 2008;13(1):71-80.

45. Kern H, Salmons S, Mayr W, Rossini K, Carraro U. Recovery of long-term denervated human muscles induced by electrical stimulation. Muscle Nerve. 2005;31(1):98-101

46. Dow DE, Cederna PS, Hassett CA, Kostrominova TY, Faulkner JA, Dennis RG. Number of contractions to maintain mass and force of a denervated rat muscle. Muscle Nerve. 2004;30(1):77-86

47. Dow DE, Faulkner JA, Dennis RG. Distribution of rest periods between electrically generated contractions in denervated muscles of rats. Artif Organs. 2005;29(6):432-5.

48. Gomes ARS, Soares AG, Peviani SM, Nascimento RB, Moriscot AS, Salvini TF. The effect of 30 minutes of passive stretch of the rat soleus muscle on the myogenic differentiation, myostatin and atrogin-1 gene expressions. Arch Phys Med Rehabil. 2006;87(2):241-6. 
49. Coutinho EL, DeLuca C, Salvini TF, Vidal BC. Bouts of passive stretching after immobilization of the rat soleus muscle increase collagen macromolecular organization and muscle fiber area. Connect Tissue Res. 2006;47(5):278-86.

50. Gajdosik RL. Passive extensibility of skeletal muscle: review of literature with clinical implications. Clin Biomech (Bristol, Avon). 2001;16(2):87-101.

51. Batista LH, Camargo PR, Oishi J, Salvini TF. Effects of an active eccentric stretching program for the knee flexor muscles on range of motion and torque. Rev Bras Fisioter. 2008;12(3):176-82.

52. Batista LH, Vilar AC, de Almeida Ferreira JJ, Rebelatto JR, Salvini TF. Active stretching improves flexibility, joint torque, and functional mobility in older women. Am J Phys Med Rehabil. 2009;88(10):815-22

53. Tabary JC, Tabary C, Tardieu C, Tardieu G, Goldspink G. Physiological and structural changes in the cat's soleus muscle due to immobilization at different lengths by plaster casts. J Physiol. 1972;224(1):231-44.

54. Williams PE, Goldspink $G$. The effect of immobilization on the longitudinal growth of striated muscle fibers. J Anat. 1973;116(Pt 1):45-65.

55. Bandy WD, Irion JM. The effect of time on static stretch on the flexibility of the hamstring muscles. Phys Ther. 1994;74(9):845-52.
56. Goldspink G, Williams P, Simpson H. Gene expression in response to muscle stretch. Clin Orthop Relat Res. 2002;1:S146-52.

57. Goldspink G, Harridge SD. Growth factors and muscle ageing. Exp Gerontol 2004;39(10):1433-8.

58. De Deyne PG. Application of passive stretch and its implications for muscle fibers. Phys Ther 2001;81(2):819-27.

59. Peviani SM, Gomes ARS, Moreira RFC, Moriscot AS, Salvini TF. Short bouts of stretching increase myo-d, myostatin and atrogin-1 in rat soleus muscle. Muscle Nerve. 2007;35(3):363-70.

60. Carmeli E, Moas M, Reznick AZ, Coleman R. Matrix metalloproteinases and skeletal muscle: a brief review. Muscle Nerve. 2004;29(2):191-7.

61. Peviani SM, Gomes AR, Selistre de Araujo HS, Salvini TF. MMP-2 is not altered by stretching in skeletal muscle. Int J Sports Med. 2009;30(7):550-4.

62. Loughna PT, Morgan MJ. Passive stretch modulates denervation induced alterations in skeletal muscle myosin heavy chain mRNA levels. Pflugers Arch. 1999;439(1-2):52-5.

63. Sakakima $H$, Yoshida $Y$. Effects of short duration static stretching on the denervated and reinnervated soleus muscle morphology in the rat. Arch Phys Med Rehabil. 2003;84(9):1339-42. 